Research Article

\title{
Characteristics of the In Situ Stress Field and Engineering Effect along the Lijiang to Shangri-La Railway on the Southeastern Tibetan Plateau, China
}

\author{
Chunyang Chai, ${ }^{1,2}$ Sixiang Ling $\mathbb{D}^{1,3}$ Xiyong Wu, ${ }^{1,3}{\text { Ting Hu, }{ }^{4} \text { and Dai Sun }}^{5}$ \\ ${ }^{1}$ Faculty of Geosciences and Environmental Engineering, Southwest Jiaotong University, Chengdu, Sichuan 611756, China \\ ${ }^{2}$ China Railway Eryuan Engineering Group Co. Ltd (CREEC), Chengdu, Sichuan 610031, China \\ ${ }^{3}$ Moe Key Laboratory of High-speed Railway Engineering, Ministry of Education, Southwest Jiaotong University, Chengdu, \\ Sichuan 610031, China \\ ${ }^{4}$ Sichuan Vocational School of Communication, Chengdu, Sichuan 611230, China \\ ${ }^{5}$ Sichuan Transportation Investment Group, Chengdu, Sichuan 610041, China
}

Correspondence should be addressed to Sixiang Ling; lingsx@swjtu.edu.cn

Received 3 October 2020; Revised 17 February 2021; Accepted 5 March 2021; Published 22 March 2021

Academic Editor: Dawei Yin

Copyright (c) 2021 Chunyang Chai et al. This is an open access article distributed under the Creative Commons Attribution License, which permits unrestricted use, distribution, and reproduction in any medium, provided the original work is properly cited.

\begin{abstract}
This work aims to characterize the in situ stress field along the Lijiang to Shangri-La railway and identify possible engineering geological problems when constructing tunnels along this railway on the margin of the Tibetan Plateau. The in situ stress measured at 76 points in 12 boreholes by the hydraulic fracturing method was analysed. A rose diagram of the maximum principal stress direction was plotted based on the measured in situ stress data. The results show that the measured in situ stress is mainly horizontal stress, corresponding to a strike-slip fault-related tectonic stress field with a moderate to high in situ stress value. The main stress values have a good linear relationship with the burial depth, and the maximum horizontal principal stress $\left(\sigma_{\mathrm{H}}\right)$ increases by 1.1-8.8 MPa per $100 \mathrm{~m}$, with an average gradient value of $3.6 \mathrm{MPa}$ per $100 \mathrm{~m}$. The maximum and minimum horizontal principal stresses and the stress differences increase with depth, and the lateral pressure coefficient $\left(\sigma_{H /} \sigma_{v}\right)$ is generally 1-1.5. The ratio of the maximum and minimum effective stresses is less than the threshold at which faulting occurs, resulting in faults that are relatively stable at present. The direction of the maximum horizontal principal stress is oriented at a small angle to the axial direction of the deeply buried tunnel along the railway line; therefore, the tunnel sidewalls could readily deform during the construction process. Rock bursts are expected to occur in strong rock masses with high risk grades, whereas slight to moderate deformation of the rock surrounding the tunnel is expected to occur in weak rock masses. This study has significance for understanding the regional fault activity and issues related to the construction of deeply buried tunnels along the Lijiang to Shangri-La railway.
\end{abstract}

\section{Introduction}

In situ stress is a fundamental parameter in a wide range of endeavours in rock mechanics and engineering construction, and it is related to many engineering problems, such as rock bursts, rock slack, and rock deformation [1-4]. Since A. Heim (1912) proposed the concept of in situ stress in an Alpine tunnel project [5], the in situ stress theory has been widely applied in underground tunnel projects. In general, the in situ stress can be measured in the field or simulated by finite element models or other model codes. A series of in situ stress measurement techniques have been developed to interpret stress in different geological conditions at a given point $[1,2]$. In situ stress measurement methods include the hydraulic fracturing method [2, 6-9], stress relief method [7-10], flat jacking method [9], borehole breakout method [9], drillinginduced tensile fracture method [11], acoustic emission method [12], strain recovery method [9], differential strain 
curve analysis method [9, 13], and geophysical method [9]. Among them, the hydraulic fracturing method and the stress relief method with overcoring are usually employed for in situ stress measurement in projects with boreholes [6-10]. Additionally, numerical simulations of the in situ stress field have become an efficient approach to study the stress distribution on a regional scale [14-16]. These studies can be used to understand the different measurement approaches and analyse the in situ stress features from a 2- or 3-dimensional simulation perspective. As China's western development strategy is further implemented, the number of deep and large road and railway tunnel projects will increase in the future. Unlike shallow engineering projects, deeply buried tunnel projects feature high sidewalls, large spans, high in situ stresses, and complex geological conditions [12-16]. The deformation or damage of the rocks surrounding deeply buried tunnels is distinctly influenced by the in situ stress field. Here, in situ stress not only determines the stability of surrounding rock masses but also acts as a load that can cause deformation and damage in tunnel projects. Therefore, determining the regional in situ stress characteristics is a prerequisite for analysing the stability of a surrounding rock mass, realizing the excavation design of underground projects, and conducting scientific decision-making.

As the region with the most intense tectonic activity on the margin of the Tibetan Plateau, the region between Lijiang and Shangri-La is characterized by large-scale active faults with a dense distribution. These long faults exhibit frequent, largemagnitude seismic activity and large displacements, which leads to a very complex in situ stress field. The railway from Lijiang to Shangri-La features numerous tunnels, and the stability of the surrounding rocks is closely related to the stress state of the rock masses (Figure 1). Many scholars have explored the region's tectonic stress field and other crustal dynamics through the analysis of focal mechanism solutions, the fault fracture modes, the characteristics of crustal deformation, inversion of the drainage pattern, stress measurements, and physical model tests in the Lijiang and Shangri-La regions [19-24]. However, the in situ stress cannot be effectively verified from the previous literature because of the limited number of measurement points. On this basis, a systematic in situ stress test using the hydraulic fracturing method was applied to boreholes that were drilled to survey the site of a proposed deeply buried tunnel project along the Lijiang to Shangri-La railway. The in situ stress was characterized from the geomechanics perspective, and the effects of fault activity and construction of a deeply buried tunnel on rock bursts and large deformations were also evaluated. This work not only provides insight into the in situ stress characteristics on the margin of the Tibetan Plateau but is also useful for tunnel axial arrangement and lining design for the Lijiang to Shangri-La railway.

\section{Geological Setting}

The region between Lijiang and Shangri-La in Yunnan, China, is located in the rhombus-shaped Sichuan-Yunnan fault block on the southeastern margin of the Tibetan Plateau (Figure 1(a)). This area is part of the middle section of the Hengduan Mountains, representing the frontal part of the suture zone between the Indian Plate and the Eurasian Plate. The study area is adjacent to the active faults along the block boundary to the southwest and is within the Zhongdian-Dali seismic belt in the southern part of the North-South seismic belt. The study area is experiencing uplift and tectonic movement to the southeast, driven by the indention of the Indian Plate and extrusion of the Tibetan Plateau (Figure 1(a)). Therefore, the structural pattern of the study area has been strongly transformed and deformed by neotectonic movement [25-27], and the study area exhibits a NNW-SSE stress direction according to the World Stress Map (Figure 1(b)) [18, 28]. There are many deep and large active faults within the region, including the ZhongdianHailuo fault, the Xiaozhongdian-Daju fault, the Xiaojin River-Lijiang fault, the Zhongdian-Longpan-Qiaohou fault, and the Daju-Lijiang fault. These faults have accommodated intense active tectonic movement around the Tibetan Plateau in China. The railway from Lijiang to Shangri-La is oriented in the NNW direction and crosses the Xiaojin River-Lijiang fault, the Daju-Lijiang fault, and the Zhongdian-Longpan-Qiaohou fault, as shown in Figure 1(c). In the Quaternary period, the regional stress field was oriented in the NNE direction during the early Pleistocene period, shifted to the E-W direction in the late early Pleistocene to the early late Pleistocene period, and finally shifted to the NNW direction in the middle period of the late Pleistocene. The present crustal stress direction continues to be oriented in the NNW direction according to the World Stress Map (Figure 1(b)) $[18,26]$. In particular, the stress fields with NNE and NNW directions were associated with the development phase of a fault basin in northwestern Yunnan, while the stress field with the E-W direction coincided with the highly differentiated uplift and subsidence phase [29].

\section{In Situ Stress Measurement Method}

The in situ stress measurement was conducted based on the boreholes drilled as part of the deeply buried tunnel survey. Considering the feasibility of measuring the in situ stress in deep holes and the working conditions in situ, the hydraulic fracturing technique was chosen as the main method to measure the in situ stress along the Lijiang to Shangri-La railway. However, there are still some limitations because the surface measurements should be done in vertical or subvertical boreholes. Here, 12 deep boreholes with 76 in situ measurement points in the proposed deeply buried tunnel were selected for the in situ stress test based on the lithological characteristics, geomorphological features, and fault distribution along the Lijiang to Shangri-La railway. The hydraulic fracturing method uses high-pressure pumps to generate high water pressure that either forms new fractures or reopens preexisting fractures.

A schematic diagram of the hydraulic fracturing process and a field photograph are shown in Figure 2. The hydraulic fracturing equipment was mainly composed of two $120 \mathrm{~cm}$ long sealing packers, an impression packer, a high-pressure pump, a chart recorder, and a flow meter (Figure 2). While the flow of high-pressure fluid between the oil pump and the sealing packers occurred via a pressure-resistant hose, the 


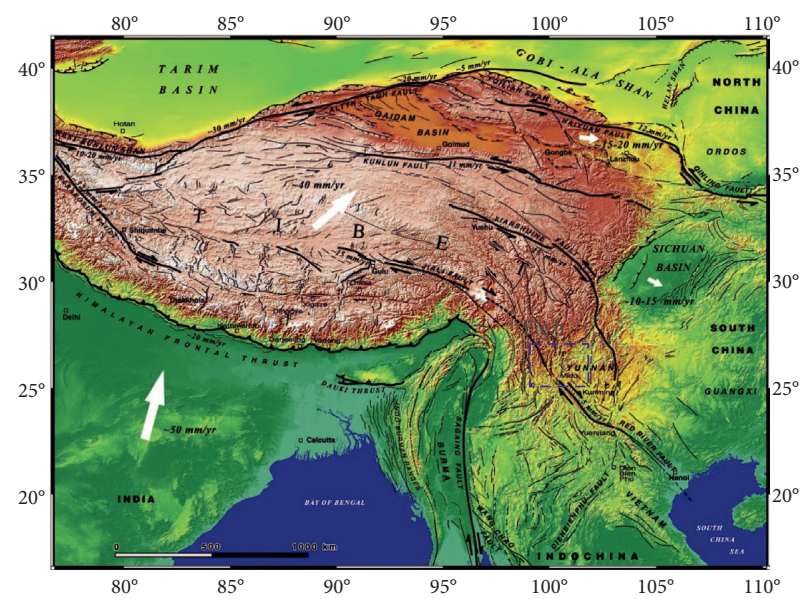

(a)

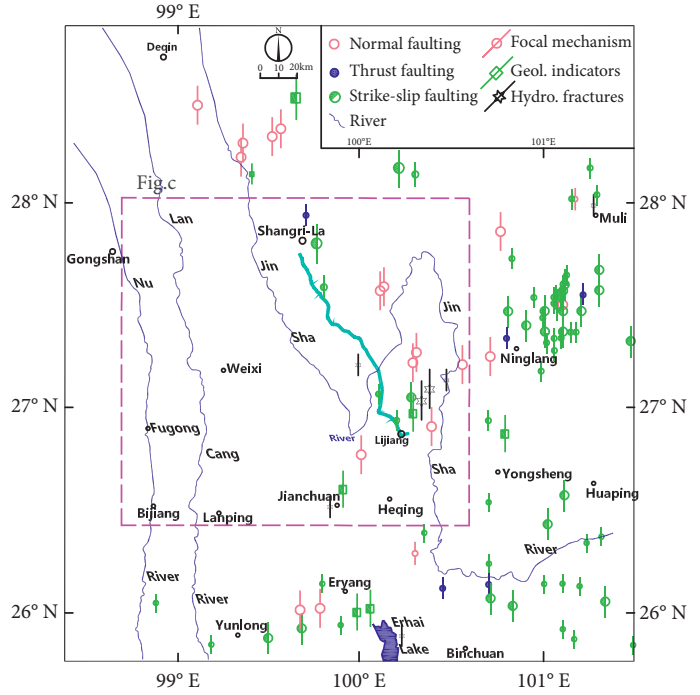

(b)

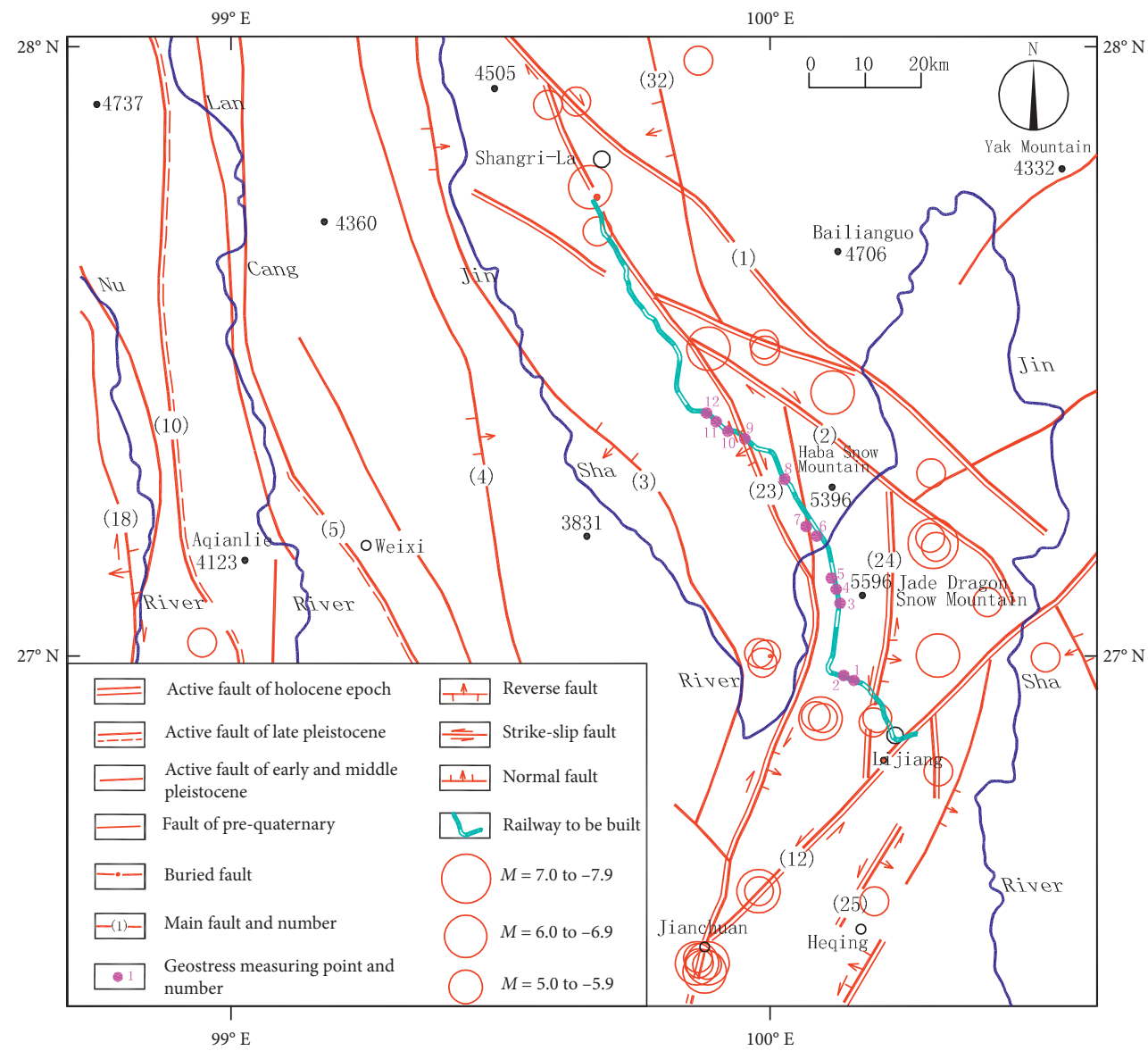

(c)

Figure 1: Topography and geologic structure map of the study area. (a) Topography and principal faults in Tibet and adjacent regions [17]. (b) The stress map of the study area and adjacent regions; the stress data are quoted from Heidbach et al. [18]. (c) Geological structure map with historical earthquake epicentres in the region including the Lijiang to Shangri-La railway. 1. Zhongdian-Hailou Fault; 2. Xiaozhongdian-Daju Fault; 3. Tacheng-Hongyan Fault; 4. Jinsha River Fault; 5. Weixi-Qiaohou Fault Zone; 6. Red River Fault Zone; 7. Longwang Temple Fault Zone; 10. Lancang River Fault Zone; 12. Xiaojin River-Lijiang Fault Zone; 18. Nujiang River Fault Zone; 19. Baoshan-Shidian Fault; 23. Zhongdian-Longpan-Qianhou Fault Zone; 24. Daju-Lijiang Fault Zone; 25. Heqing Fault Zone; 32. Xiangcheng-Gezan Fault. 


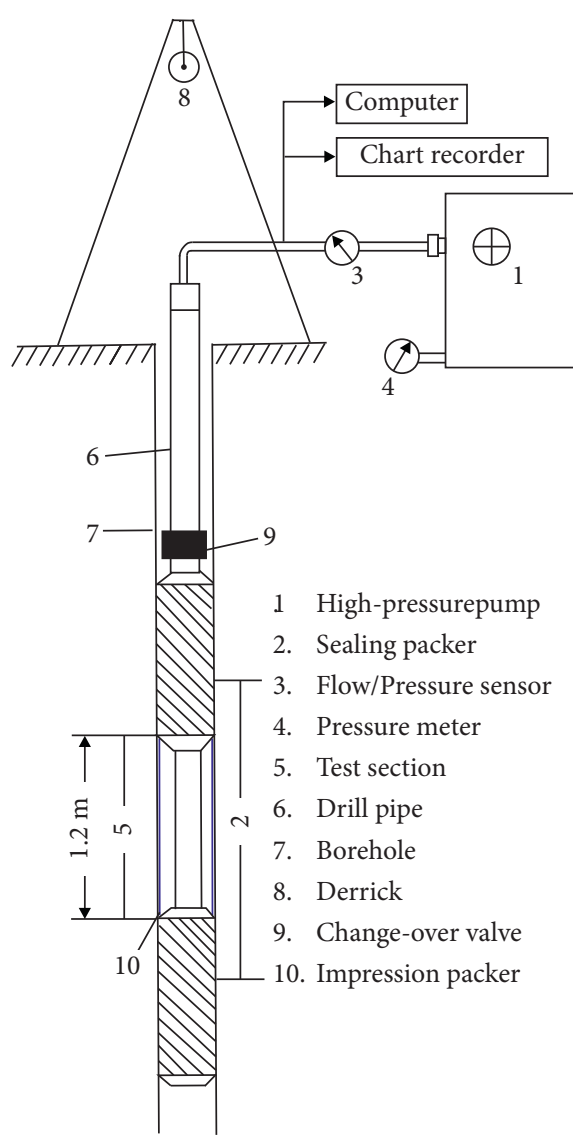

(a)

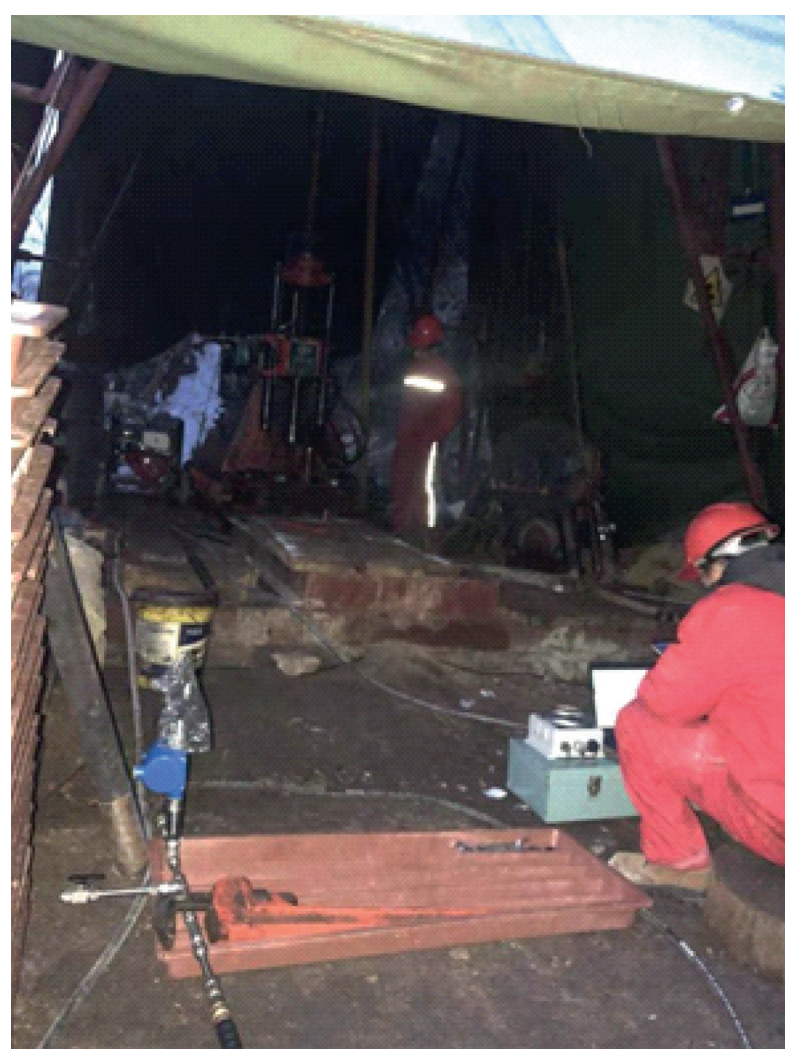

(b)

FIGURE 2: Hydraulic fracturing measurement method. (a) Schematic diagram with the hydraulic fracturing equipment; (b) field photograph of the measurement process.

flow between the water pump and the isolated test section of the borehole occurred via drilling rods, which enabled the packers to be hoisted easily. This generates tensile stresses in the borehole wall. Pressurisation continues until the borehole wall ruptures through tensile failure and hydrofracturing is initiated. The hydraulic fracturing pressure and calculation of the in situ stress are described in detail by Haimson and Cornet [6]. The hydraulic fracturing method allows a direct measurement of the minimum stress in the plane perpendicular to the borehole axis, which is normally the minimum horizontal principal stress $\left(\sigma_{\mathrm{h}}\right)$, and the accuracy is good $(<\sim \pm 3 \%)$. The maximum horizontal stress is calculated from equations that include failure criteria and parameters evaluated from the field pressure data. The accuracy is lower for the maximum horizontal principal stress $\left(\sigma_{\mathrm{H}}\right)$, with an error of $\sim \pm 3-8 \%$. The orientation of the maximum horizontal principal stress is accurate to less than $\pm 5^{\circ}$, corresponding to the A-quality class as defined as within $\pm 15^{\circ}$ by Heidbach et al. [18]. In the Lijiang to Shangri-La railway, 76 data points were obtained from the studied boreholes, as shown in Table 1.

\section{Results of In Situ Stress and Faults}

4.1. Type of In Situ Stress Field. Among the 76 in situ measured points in the 12 drilling boreholes, 64 data points have a maximum horizontal principal stress $\left(\sigma_{\mathrm{H}}\right)$ larger than the vertical principal stress $\left(\sigma_{\mathrm{v}}\right)$, accounting for $84.2 \%$ of the total measured points. The other 12 data points of maximum horizontal principal stress are less than the vertical principal stress, accounting for $15.8 \%$ of the total measured points. Therefore, the horizontal in situ stress is the dominant stress in the rocks along the Lijiang to Shangri-La railway, and this stress predominantly results from tectonic stress. This in situ stress field represents a typical tectonic stress field. Among the 76 in situ measured points, there are 10 measured points with $\sigma_{\mathrm{H}}>\sigma_{\mathrm{h}}>s_{\mathrm{v}}$ or $\sigma_{\mathrm{v}}>\sigma_{\mathrm{H}}>\sigma_{\mathrm{h}}$, accounting for $13.2 \%$ of the total measured points. However, there are still 56 points with $\sigma_{\mathrm{H}}>\sigma_{\mathrm{v}}>\sigma_{\mathrm{h}}$, accounting for $73.6 \%$ of the total measured points and showing that the in situ stress field is conducive to the formation of strike-slip faults. The western boundary of the Zhongdian-Longpan-Qiaohou fault (No. 23 in Figure 1(c)) presents dextral strike-slip offset features [30], and the horizontal displacement is larger than the vertical displacement, as determined with the Global Positioning System (GPS) technique. This GPS observation result is consistent with the results of the in situ stress measurement. From the geodynamics perspective, the horizontal stress of the in situ stress field dominates the tectonic stress field and is mainly produced by the eastward movement of the Tibetan block due to the collision of the Indian Plate and the 


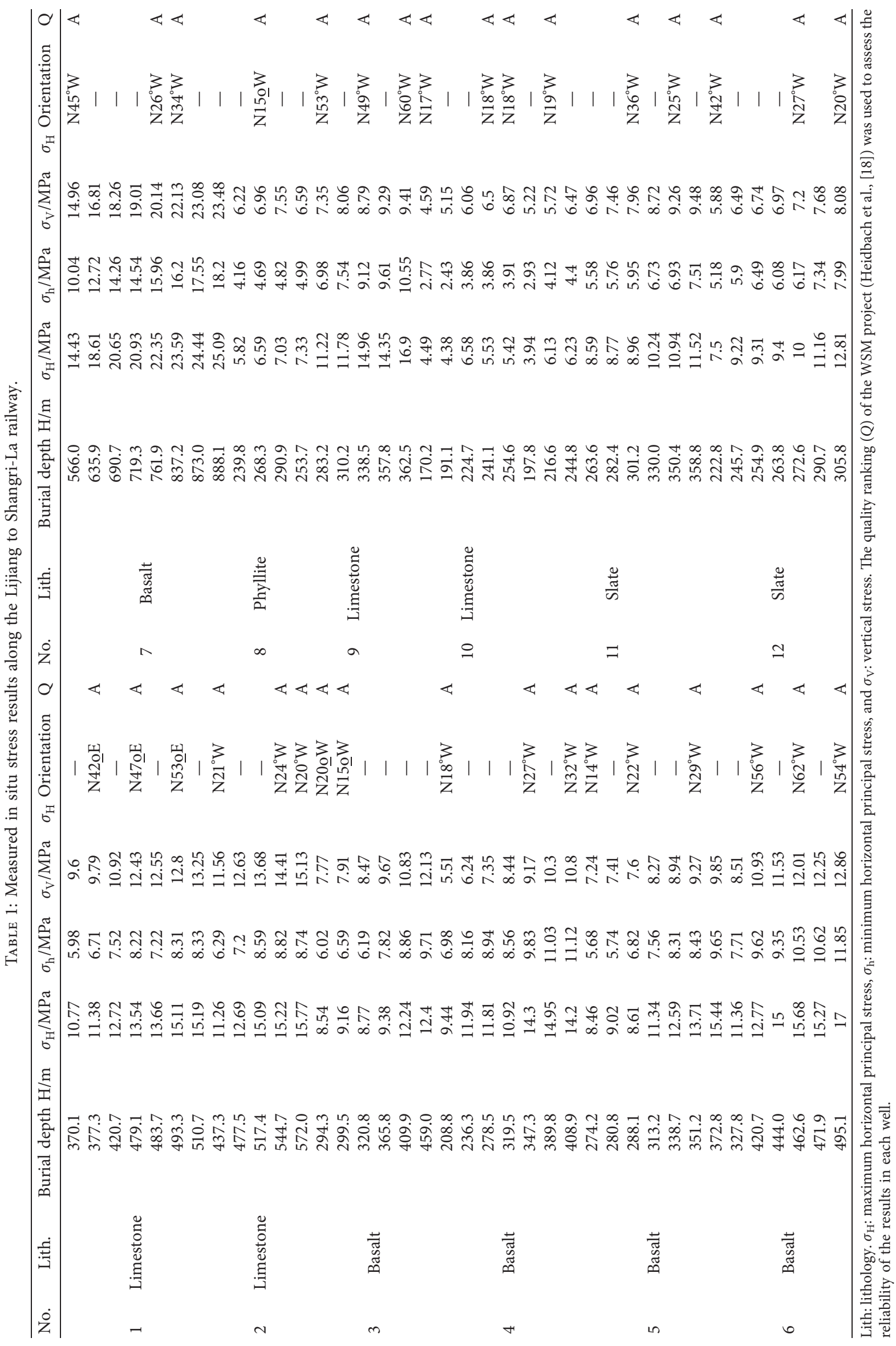


Eurasian Plate (Figure 1(a)) [17, 31]. The rhombus-shaped block of the western Zhongdian-Longpan-Qiaohou fault rotates clockwise under the horizontal stress oriented in the SE and SSE directions. Consequently, this rhombus-shaped block is characterized by greater displacement in the south and west than in the north and east.

4.2. Characteristics of the Horizontal Principal Stress Orientation. The rose chart of the horizontal principal stress orientation and focal mechanism solution is illustrated in Figure 3. According to the statistical analysis, $\mathrm{N} 10^{\circ}-60^{\circ} \mathrm{W}$ is the dominant orientation of the maximum horizontal principal stress $\left(\sigma_{\mathrm{H}}\right)$, which results in a predominant orientation of $\mathrm{N} 15^{\circ} \mathrm{W}$ (Figure 3(a)). Moreover, the principal stress orientation and predominant orientation of the modern tectonic stress field are $\mathrm{N} 35^{\circ}-5^{\circ} \mathrm{W}$ and $\mathrm{N} 15^{\circ} \mathrm{W}$, respectively, according to the analysis of focal mechanism solutions in the northwestern Yunnan region (Figure 3(b)) [32]. However, the World Stress Map of the region (Figure 1(b)) suggests that the dominant orientation is N-S with an error of $\pm 15^{\circ}-25^{\circ}$. Compared with that of the World Stress Map, the horizontal principal stress orientation from on-site measurements is accurate to less than $\pm 5^{\circ}$, indicating that on-site measurements more accurately reflect the in situ stress field along the Lijiang to Shangri-La railway. From the structural trace perspective, fault scars suggest that the regional principal stress field has been oriented to the NNW from the middle period of the late Pleistocene to the present [33]. The result from structural traces is generally consistent with the horizontal stress orientation from the on-site measurement. However, some on-site points reflect local stress characteristics, which are controlled by the local landforms, lithology, crustal structure, etc. In particular, borehole No. 1 exhibited a local stress field related to its position near a deep gorge, and the principal stress was rotated towards the river valley, with the maximum horizontal stress oriented in the direction of $\mathrm{N} 42^{\circ}-53^{\circ} \mathrm{E}$. Meanwhile, the principal stress of borehole No. 9, which is located near the Chongjiang River fault (striking N32 $\mathrm{W}$ ), is affected by the fault and is deflected in the direction of $\mathrm{N} 50^{\circ}-60^{\circ} \mathrm{W}$.

\subsection{In Situ Stress Characteristics Relationship with Depth}

4.3.1. Variation Pattern of the Principal Stress with Depth. Statistical analysis of the data in Table 1 shows that the maximum horizontal principal stress is 3.94-25.09 $\mathrm{MPa}$, and the stress gradient is $1.1-8.8 \mathrm{MPa} / 100 \mathrm{~m}$, with an average of $3.6 \mathrm{MPa} / 100 \mathrm{~m}$. The minimum horizontal principal stress is $2.43-18.2 \mathrm{MPa}$, and the stress gradient is $1.3-5.1 \mathrm{MPa} / 100 \mathrm{~m}$, with an average of $2.6 \mathrm{MPa} / 100 \mathrm{~m}$. A scatter diagram of the in situ stress relationship with burial depth is plotted in Figure 4. The relationship between the horizontal principal stress and the burial depth was determined by the least square linear regression method. The maximum horizontal principal stress is $\sigma_{H}=1.853+0.0266 \mathrm{H}$, with a correlation coefficient $R^{2}=0.702$, and the minimum horizontal principal stress is $\sigma_{h}=1.043+0.0182 \mathrm{H}$, with an $R^{2}=0.627$. As shown in Figure 4, the maximum and minimum horizontal principal stresses basically increase with burial depth and exhibit good linear relationships. However, the horizontal principal stresses still exhibit discrete phenomena when the burial depth is less than $600 \mathrm{~m}$, with the largest difference of 5-6 MPa at a burial depth of approximately $380 \mathrm{~m}$.

4.3.2. Variation Pattern of the Lateral Pressure Coefficient with Depth. The lateral pressure coefficient (LPC, $\left.\sigma_{H /} \sigma_{v}\right)$ is the ratio of the maximum horizontal principal stress and the vertical stress, which is illustrated in Figure 5. The LPC generally ranges from 0.75 to 1.91 , with an average value of 1.21. The LPC is higher than 1 at 64 on-site measured points, accounting for $84 \%$ of the total measured points. The LPC ranged between 1.0 and 1.5 at 54 of the 64 points, accounting for $71 \%$ of the 64 points. However, the LPC at the other 10 points ranged from 1.5 to 2.0 , accounting for $13 \%$. This result indicates that regional stress is dominated by tectonic stress. Here, the in situ stress in our study area can reach a moderate to high level, which is based on the criterion of the in situ stress field from Xue et al. [34]. The LPC shows great discreteness when the burial depth is shallower than $400 \mathrm{~m}$. However, the LPC gradually approaches 1 as the burial depth increases (Figure 5), indicating that the horizontal stress or tectonic stress becomes equal to the gravitational stress.

4.3.3. Variation Pattern of the Horizontal Stress Difference with Depth. The regional horizontal shear stress can be indirectly reflected by the difference between the maximum and minimum horizontal principal stresses [18, 33]. The scatter diagram of horizontal stress differences $\left(\Delta \sigma_{H-h}\right)$ with burial depth is illustrated in Figure 6. The relationship between $\Delta \sigma_{H-h}$ and burial depth $(\mathrm{H})$ is $\Delta \sigma_{H-h}=0.0084 H$ $+0.8103, R^{2}=0.6301$, based on linear least square regression. The scatter diagram shows that $\Delta \sigma_{H-h}$ increases with burial depth, which results in the gradual increase in $\Delta \sigma_{H-h}$ from $1 \mathrm{MPa}$ at approximately $200 \mathrm{~m}$ depth to $7.4 \mathrm{MPa}$ at approximately $850 \mathrm{~m}$ (Figure 6).

4.4. Fault Characteristics along the Lijiang to Shangri-La Railway. The Lijiang to Shangri-La railway crosses the Xiaojin River-Lijiang fault, the Daju-Lijiang fault, and the Zhongdian-Longpan-Qiaohou fault from south to north, as illustrated in Figure 1(c) and Table 2. The Xiaojin River-Lijiang fault zone does not show obvious signs of Quaternary deformation and is mainly associated with erosional linear depressions and drainage systems eroding the preexisting thrust belt. The Xiaojin River-Lijiang fault was an active thrust fault with a left-lateral component in the Neogene-early Pleistocene $\left(N-Q_{1}\right)$ period, with a maximum historical earthquake magnitude of approximately M 6.1 (Table 2). The Lijiang-Daju fault controls the fault depressions in the subsided Lijiang-Daju basin with a maximum depth of $>1200 \mathrm{~m}$ and was active in the late Quaternary $\left(Q_{3}-Q_{4}\right)$ period $[23,24]$. The Lijiang-Daju fault is a normal fault with a left-lateral component and a maximum earthquake magnitude of $\mathrm{M} 7.0$ in 1996. The Lijiang-Daju fault is characterized by fault 


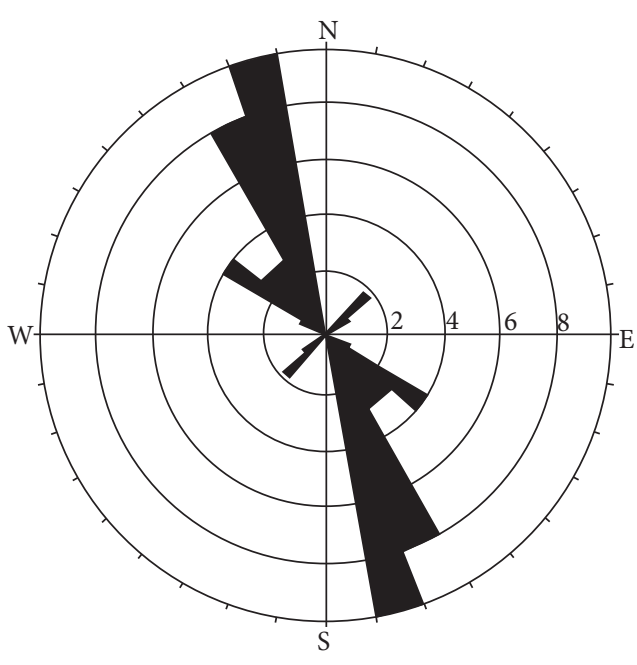

(a)

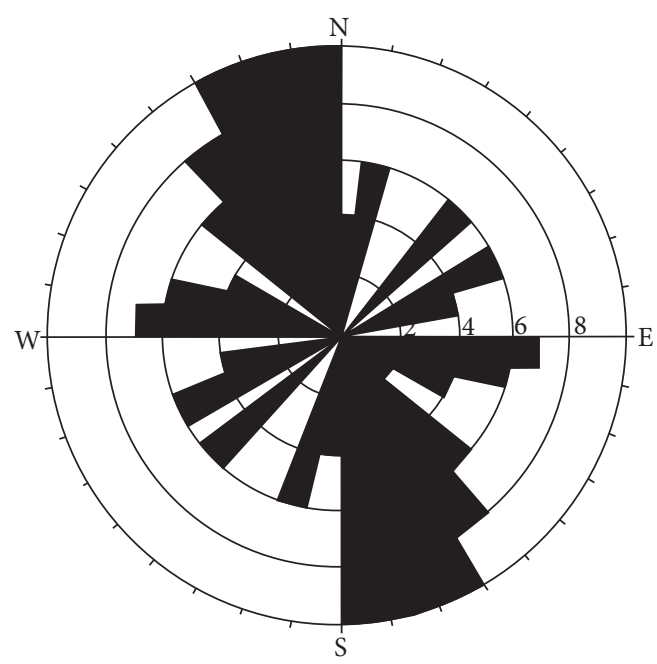

(b)

FIgURE 3: Direction of the maximum horizontal principal stress. (a) Measured in situ stress; (b) focal mechanism solution.

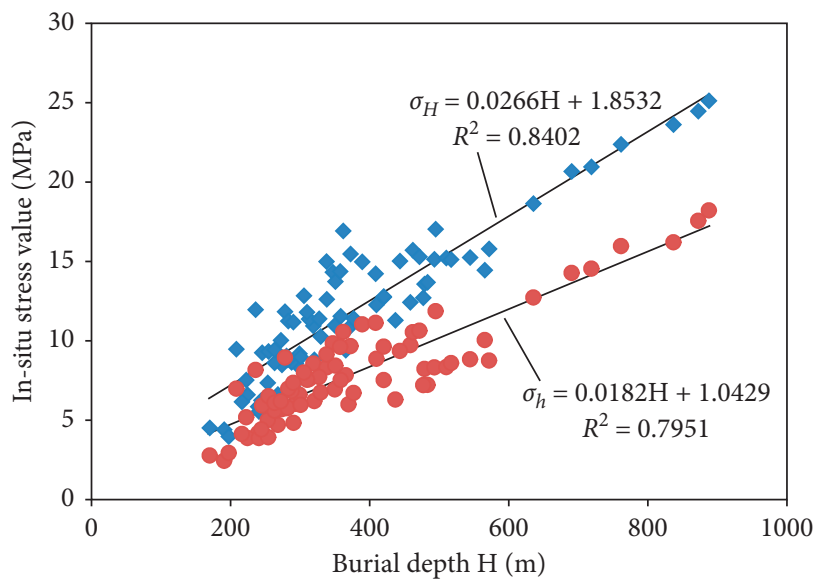

- Maximum horizontal principal stress $\left(\sigma_{H}\right)$

- Minimum horizontal principal stress

FIGURE 4: Relationship between the horizontal principal stress and burial depth $\mathrm{H}$.

triangles, fault scarps, and escarpments composed of dislocated late Quaternary strata, and broken strata with traction deformation are observed. The Longpan-Qiaohou fault shows obvious Quaternary activity and great deformation in the fault zone, resulting in an inconsistent distribution of strata on either side and large differences in occurrence. The LongpanQiaohou fault is a thrust fault with a right-lateral component and a historical maximum earthquake magnitude of $M 63 / 4$ in 1751 (Table 2). Along the Longpan-Qiaohou fault, Quaternary fault basins, such as the Jiuhe, Jianchuan, and Shaxi basins, have developed, and the maximum deposition thickness has reached $>600 \mathrm{~m}$ in the Jianchuan Basin. The Zhongdian fault is located on the northern side of the railway and was active in the Quaternary, specifically during the late Pleistocene to Holocene, and it is responsible for the formation of the

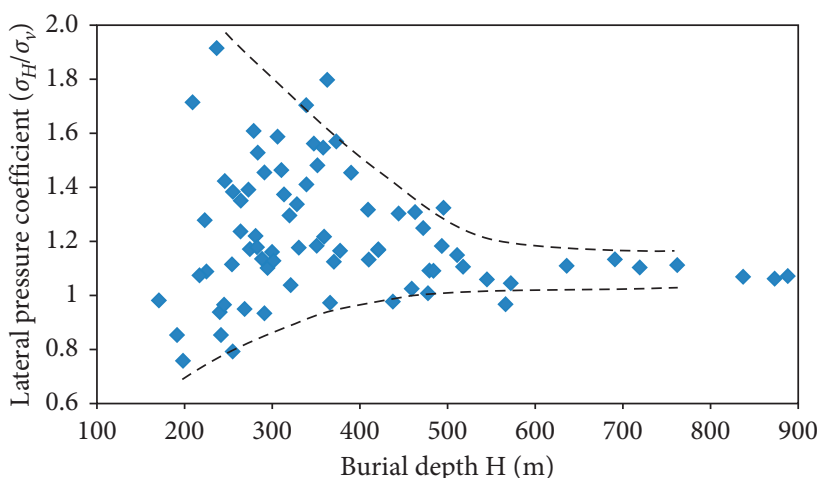

Figure 5: Relationship between the lateral pressure coefficient (LPC, $\sigma_{H /} \sigma_{v}$ ) and the burial depth.

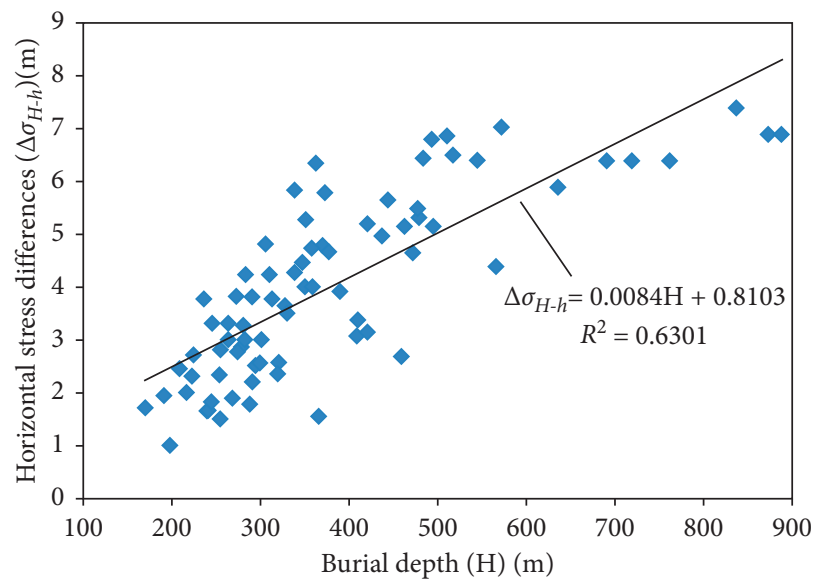

FIGURE 6: Scatter diagram between the horizontal stress difference $\left(\Delta \sigma_{H-h}\right)$ and the burial depth.

Zhongdian and Xiaozhongdian depression basins [23, 24]. The Zhongdian fault is a right-lateral strike-slip fault with a maximum earthquake magnitude of 6\%1/4 in 1933. 
TABLE 2: The main characteristics of active faults along the Lijiang to Shangri-La railway from south to north.

\begin{tabular}{|c|c|c|c|c|c|c|c|c|}
\hline \multirow[b]{2}{*}{ No. } & \multirow[b]{2}{*}{ Fault name } & \multicolumn{5}{|c|}{ Attitude of fault } & \multirow[b]{2}{*}{$\begin{array}{l}\text { Epoch of latest } \\
\text { activity }\end{array}$} & \multirow[b]{2}{*}{ Seismic activity } \\
\hline & & Length & Strike & Dip & $\begin{array}{c}\text { Dip } \\
\text { angle }\end{array}$ & Fracture property & & \\
\hline 12 & $\begin{array}{c}\text { Xiaojin river-Lijiang } \\
\text { fault }\end{array}$ & 70 km & $\mathrm{NE}$ & NW & $60^{\circ}-80^{\circ}$ & Left-reverse & $\mathrm{N}-\mathrm{Q}_{1}$ & $\begin{array}{l}\text { M } 6.1 \text { in } 1951 \\
\text { M } 6 \text { in } 1996\end{array}$ \\
\hline 24 & $\begin{array}{l}\text { Lijiang-Dajun fault } \\
\text { zone }\end{array}$ & $55 \mathrm{~km}$ & $\begin{array}{c}\text { Close to } \\
\text { SN }\end{array}$ & $\begin{array}{l}\text { E/ } \\
\mathrm{W}\end{array}$ & $60^{\circ}-80^{\circ}$ & Left-normal & $\mathrm{Q}_{3}-\mathrm{Q}_{4}$ & M 7.0 in 1996 \\
\hline 23 & $\begin{array}{c}\text { Longpan-Qiaohou } \\
\text { fault }\end{array}$ & $110 \mathrm{~km}$ & $\begin{array}{l}\text { NNW- } \\
\text { NNE }\end{array}$ & $\mathrm{W}$ & $60^{\circ}-80^{\circ}$ & Right-reverse & $\mathrm{Q}_{3}-\mathrm{Q}_{4}$ & $\begin{array}{c}\text { M 6(1/4) in } 1688, \text { M } 6(3 / 4) \\
\text { in } 1751 \\
\text { M } 6 \text { in } 1961\end{array}$ \\
\hline 23 & Zhongdian fault & $60 \mathrm{~km}$ & NW & $\mathrm{NE}$ & $70^{\circ}$ & $\begin{array}{l}\text { Right-lateral } \\
\text { strike-slip }\end{array}$ & $\mathrm{Q}_{3}-\mathrm{Q}_{4}$ & M 6(1/4) in 1933 \\
\hline
\end{tabular}

The fault number is shown in Figure $1(\mathrm{c})$. N: Neogene; $Q_{1}$ : Lower Pleistoncene; $Q_{2}$ : Middle Pleistoncene; $Q_{3}$ : Upper Pleistoncene; $Q_{4}$ : Holocene.

\section{Analysis and Discussion}

5.1. Activity of the Fault. Fault activities mainly include stickslip movement and creep movement. Creep movement gradually releases crustal energy, which causes many consecutive earthquake events and crustal deformation. However, stick-slip movement is associated with abrupt changes and results in displacement, crustal rupture, and surface deformation and is always associated with an earthquake event with a number of aftershocks after a long quiescent period [19-22]. According to the frictional sliding criterion of faults, the relationship between the crustal stress state and fault activity follows Coulomb's law of friction. Assuming that the cohesion (intrinsic strength) of a fault is 0 and considering the concepts of effective stress, average stress, and maximum shear stress, the formula of seismic activity can be obtained as follows [35]:

$$
K=\left(\sigma_{1}-U_{0}\right) /\left(\sigma_{3}-U_{0}\right) \leq\left[\left(1+\mu^{2}\right)^{0.5}+\mu\right]^{2}=\mu_{m}
$$

In the formula, $\sigma_{1}$ and $\sigma_{3}$ are the maximum and minimum principal stresses on the periphery of the fracture. For strike-slip fault activity, $\sigma_{1}$ and $\sigma_{3}$ are equal to the maximum horizontal stress $\sigma_{\mathrm{H}}$ and the minimum principal stress $\sigma_{\mathrm{h}}$, respectively, but for reverse fault activity, $\sigma_{1}$ and $\sigma_{3}$ are the maximum horizontal stress $\sigma_{\mathrm{H}}$ and the vertical principal stress $\sigma_{\mathrm{v}}$, respectively. $\mathrm{U}_{0}$ is the pore pressure, and $\mu$ is the friction coefficient of the fault. The friction coefficient $(\mu)$ was equal to $0.5-0.7$ if the pore water pressure was ignored [36-38]; however, $\mu$ should be $0.6-1.0$ to evaluate the shallow fault activity $[37,38]$.

If the ratio of the maximum and minimum effective principal stresses $\left(\sigma_{1} / \sigma_{3}\right)$ is less than or equal to $\mu_{\mathrm{m}}$, from equation (1), the faults are stable. However, if this ratio $\left(\sigma_{1} /\right.$ $\left.\sigma_{3}\right)$ is larger than $\mu_{\mathrm{m}}$, faulting will occur. If the pore water pressure is ignored and $\mu=0.5$ is the critical friction coefficient of a fault instability, a value of $\mu_{\mathrm{m}}=2.6$ can be inferred. After applying the in situ stress data from Table 1 in equation (1), the $K$ value is in the range of $1.2-1.9$, which is less than 2.6, indicating that the ratio of the maximum and minimum effective stresses $\left(\sigma_{1} / \sigma_{3}\right)$ in the study area is less than the critical value at which faulting will occur and that the faults are relatively stable at present. This result may be affected by the Ms 7.0 Lijiang earthquake and its aftershocks in 1996, which resulted in the release of crustal energy to a certain extent and, consequently, a reduction in the stress level to some extent.

5.2. Stability of a Rock Mass in Tunnel Cavern. The principal stress along the Lijiang to Shangri-La railway is dominated by intense compression in the horizontal direction. The Lijiang to Shangri-La railway line is oriented in the northsouth direction at a small angle to the maximum horizontal principal stress direction. Additionally, the shear failure of a rock mass mainly depends on the principal stress difference. The larger the burial depth of the underground excavation is, the larger the difference between the maximum and minimum principal stresses and the lower the stability of the surrounding rocks. According to the energy dissipation and energy release principles [39], as shown in equation (2), the maximum release rate of the destructive energy of the surrounding rocks appears in the direction of the minimum principal stress, which is unfavourable for the stability of the sidewalls of a tunnel. When the surrounding rocks are damaged by in situ stress, the energy release rate in the principal stress direction is proportional to the stored elastic strain energy and principal stress difference $(\Delta \sigma)$. The energy release rate increases with increasing burial depth and principal stress difference $(\Delta \sigma)$. The energy release equation is as follows [39]:

$$
G_{c}=K_{3}\left(\sigma_{1}-\sigma_{3}\right) U^{e}
$$

In the formula, $K_{3}$ is the material constant, $U^{e}$ is the elastic strain energy, and $G_{c}$ is the critical value of the maximum energy release rate.

A rock mass composed of hard rock can store a very high elastic strain energy under high in situ stress conditions because it has high compressive strength and strong elasticity and brittleness parameters. The principal stress forms a stress concentration area in the surrounding walls when hard rock is excavated during the construction of a tunnel. When the principal stress of the surrounding rocks exceeds the ultimate compressive strength of the rock mass, the high strain energy of the rock mass can be released instantaneously, causing a rock burst, which 
TABLE 3: Russenes criterion of rock burst [40].

\begin{tabular}{lc}
\hline$\sigma_{\theta} / R_{\mathrm{c}}$ & Grade \\
\hline $0.20 \sim 0.30$ & Weak \\
$0.30 \sim 0.55$ & Moderate \\
$\geq 0.55$ & Strong \\
\hline
\end{tabular}

$\sigma_{\theta}$ is the tangential stress of the surrounding rocks $\left(\sigma_{\theta}=3 \sigma_{1}-\sigma_{3}\right)$, and $R_{\mathrm{c}}$ is the compressive strength of the rocks.

TABLE 4: Classification criteria of deformation [41].

\begin{tabular}{lc}
\hline$\sigma_{\max } / R_{\mathrm{c}} \cdot K_{\mathrm{v}}$ & Grade \\
\hline $0.5 \sim 0.25$ & Slight \\
$0.25 \sim 0.15$ & Moderate \\
$>0.15$ & Strong \\
\hline
\end{tabular}

$\sigma_{\max }$ is the maximum horizontal stress, and $\mathrm{Rc} \cdot \mathrm{Kv}$ is the product of the compressive strength and the integrity coefficient of rocks, which represents the compressive strength of a rock mass.

typically includes splitting, shearing, and ejection phenomena. The uniaxial compressive strength of the limestone and basalt in the tunnel along the Lijiang to ShangriLa railway ranges from 70 to $100 \mathrm{MPa}$. The maximum horizontal principal stress $\left(\sigma_{\mathrm{H}}\right)$ along the railway is 25.09 $\mathrm{MPa}$. The ratio of the tangential stress of the surrounding rocks and the compressive strength is approximately $0.6-0.8 \mathrm{MPa}$ along railway line. Based on the Russenes criterion in Table 3 [40], there is a high probability of strong rock burst phenomena in the hard rock surrounding the tunnel project along the Lijiang to Shangri-La railway.

The weak surrounding rock has low compressive strength and high plasticity. The principal stress will readjust and redistribute in the surrounding walls when excavating this weak rock during the construction of the tunnel. When the stress exceeds the resistance of the surrounding rocks to bending, the surrounding rocks above and below the tunnel could become loose, producing vertical displacement and flexural phenomena. Soft rocks, including phyllite, shale, and slate, are widely distributed along the path of the tunnel project of the Lijiang to the Shangri-La railway. This soft rock has a uniaxial compressive strength of $8-25 \mathrm{MPa}$. The ratio of the maximum horizontal stress and compressive strength along the railway line is $0.16-0.50$. Based on the strength-stress criterion in Table 4 [41], there is a high probability of slight to moderate deformation in the soft rock (e.g., phyllite, slate, and shale) surrounding the tunnel along the Lijiang to Shangri-La railway.

\section{Conclusion}

Based on the results of this study, the following conclusions can be drawn:

(1) The in situ stress field along the Lijiang to Shangri-La railway is dominated by horizontal stress, which is described by $\sigma_{\mathrm{H}}>\sigma_{\mathrm{v}}>\sigma_{\mathrm{h}}$ and belongs to the strikeslip fault-based tectonic stress field. The maximum horizontal principal stress orientation is $\mathrm{N} 10^{\circ}-60^{\circ} \mathrm{W}$, and the predominant direction is $\mathrm{N} 15^{\circ} \mathrm{W}$.
(2) The in situ stress along the Lijiang to Shangri-La railway is classified as moderate to high. The maximum and minimum horizontal principal stresses and the horizontal stress differences $\left(\Delta \sigma_{H-h}\right)$ linearly increase with increasing burial depth. Although the lateral pressure coefficient (LPC, $\sigma_{H /} \sigma_{v}$ ) displays a certain discreteness in the range of 1.0-1.5, it exhibits a decreasing trend with increasing burial depth and gradually approaches 1 asymptotically.

(3) The ratio of the maximum and minimum effective stresses along the Lijiang to Shangri-La railway is less than the critical value, indicating that the faults are still relatively stable at present. The risk probability of earthquakes is relatively low.

(4) A small angle is observed between the maximum horizontal principal stress and the axial direction of the tunnel, which is unfavourable for the stability of the sidewalls of a tunnel. A high probability of a strong rock burst exists in the intact hard rock mass. On the other hand, slight to moderate deformation is expected to occur in soft rock masses (e.g., phyllite, slate, shale) in the tunnel project along the Lijiang to Shangri-La railway.

\section{Data Availability}

The data used to support the findings of this study are available from the authors upon request.

\section{Conflicts of Interest}

The authors declare that they have no known conflicts of interest or personal relationships that could have appeared to influence the work reported in this paper.

\section{Acknowledgments}

The authors thank colleagues of China Railway Eryuan Engineering Group Co. Ltd (CREEC) and Southwest Jiaotong University for kind support in the field. This work was funded by the Key Research and Development Program of China Railway Eryuan Engineering Group Co. Ltd (CREEC) (No. KYY2017006-(17-19)) and Fundamental Research Funds for the Central Universities (No. 2682020CX11).

\section{References}

[1] X. Ge and M. Hou, "Principle of in-situ 3D rock stress measurement with borehole wall stress relief method and its preliminary applications to determination of in-situ rock stress orientation and magnitude in Jinping hydropower station," Science China Technological Sciences, vol. 55, no. 4, pp. 939-949, 2012.

[2] Z. Liu, Q. Lu, Y. Sun, X. Tang, Z. Shao, and Z. Weng, "Investigation of the influence of natural cavities on hydraulic fracturing using phase field method," Arabian Journal for Science and Engineering, vol. 44, no. 12, pp. 10481-10501, 2019.

[3] Z. Wen, Z. Xiong, H. Lu, and Y. Xia, "Optimisation of treatment scheme for water inrush disaster in tunnels based on fuzzy multi-criteria decision-making in an uncertain 
environment," Arabian Journal for Science and Engineering, vol. 44, no. 10, pp. 8249-8263, 2019.

[4] H. Q. Yang, Y. Y. Zeng, Y. F. Lan, and X. P. Zhou, "Analysis of the excavation damaged zone around a tunnel accounting for geostress and unloading," International Journal of Rock Mechanics and Mining Sciences, vol. 69, pp. 59-66, 2014.

[5] A. Heim, Bergsturz und Menschenleben, Fretz \& Wasmuth, Zürich, Switzerland, 1932.

[6] B. C. Haimson and F. H. Cornet, "ISRM Suggested Methods for rock stress estimation-Part 3: hydraulic fracturing (HF) and/or hydraulic testing of pre-existing fractures (HTPF)," International Journal of Rock Mechanics and Mining Sciences, vol. 40, no. 7-8, pp. 1011-1020, 2003.

[7] C. Fairhurst, "Stress estimation in rock: a brief history and review," International Journal of Rock Mechanics and Mining Sciences, vol. 40, no. 7-8, pp. 957-973, 2003.

[8] C. Ljunggren, Y. Chang, T. Janson, and R. Christiansson, "An overview of rock stress measurement methods," International Journal of Rock Mechanics and Mining Sciences, vol. 40, no. 78, pp. 975-989, 2003.

[9] M. F. Cai, L. Qiao, and H. B. Li, Rock Stress Measurement Principles and Techniques (in Chinese), Science Press, Beijing, China, 1995.

[10] K. Sugawara and Y. Obara, "Draft ISRM suggested method for in-situ stress measurement using the compact conical-ended borehole overcoring (CCBO) technique," International Journal of Rock Mechanics \& Mining Sciences, vol. 36, pp. 307-322, 1999.

[11] M. Brudy and M. D. Zoback, "Drilling-induced tensile wallfractures: implications for determination of in-situ stress orientation and magnitude," International Journal of Rock Mechanics and Mining Sciences, vol. 36, no. 2, pp. 191-215, 1999.

[12] A. Lavrov, "The Kaiser effect in rocks: principles and stress estimation techniques," International Journal of Rock Mechanics and Mining Sciences, vol. 40, no. 2, pp. 151-171, 2003.

[13] Y. Oikawa, I. Matsunaga, and T. Yamaguchi, "Differential strain curve analysis to estimate the stress state of the Hijiori hot dry rock field, Japan," International Journal of Rock Mechanics and Mining Sciences \& Geomechanics Abstracts, vol. 30, no. 7, pp. 1023-1026, 1993.

[14] C. Hashimoto and M. Matsu'ura, "3-D simulation of tectonic loading at convergent plate boundary zones: internal stress fields in Northeast Japan," Pure and Applied Geophysics, vol. 163, no. 9, pp. 1803-1817, 2006.

[15] Z. Wu, Y. Zuo, S. Wang et al., "Numerical study of multiperiod palaeotectonic stress fields in Lower Cambrian shale reservoirs and the prediction of fractures distribution: a case study of the Niutitang Formation in Feng'gang No. 3 block, South China," Marine and Petroleum Geology, vol. 80, pp. 369-381, 2017.

[16] J. Liu, W. Ding, H. Yang, K. Jiu, Z. Wang, and A. Li, "Quantitative prediction of fractures using the finite element method: a case study of the lower Silurian Longmaxi Formation in northern Guizhou, South China," Journal of Asian Earth Sciences, vol. 154, pp. 397-418, 2018.

[17] P. Tapponnier, Z. Xu, F. Roger et al., "Oblique stepwise rise and growth of the Tibet Plateau," Science, vol. 294, no. 5547, pp. 1671-1677, 2001.

[18] O. Heidbach, M. Rajabi, X. Cui et al., "The World Stress Map database release 2016: crustal stress pattern across scales," Tectonophysics, vol. 744, pp. 484-498, 2018.

[19] P. Molnar and P. Tapponnier, "Cenozoic Tectonics of Asia: effects of a Continental Collision: features of recent continental tectonics in Asia can be interpreted as results of the India-Eurasia collision," Science, vol. 189, no. 4201, pp. 419-426, 1975.

[20] F. Xie, G. Liu, and H. Liang, "Recent tectonic stress field in northwest Yunnan Province and its adjacent areas," Seismology and Geology, vol. 16, no. 4, pp. 329-338, 1994.

[21] Z. Hou, D. Li, and B. Wang, "Study on neotectonic stress field and present tectonic stress field in northwest Yunnan," Hydrogeology \& Engineering Geology, vol. 3, pp. 83-91, 1988.

[22] Y. Ran and X. Li, "The evolution of the tectonic stress field in northwest Yunnan during neotectonic period," Northwestern Seismology Journal, vol. 9, no. 3, pp. 84-91, 1987.

[23] S. Wang and X. Long, "Tempo-spatial variation of the ambient stress field in the seismic area before and after Lijiang earthquake," Seismological and Geoagnetic Observation and Research, vol. 19, no. 4, pp. 18-24, 1998.

[24] S. Wang, X. Long, and S. Luo, "The focal mechanism seismogenic stress field and rupture characteristics of the Lijiang earthquake sequence," Journal of Seismological Research, vol. 20, no. 1, pp. 26-34, 1997.

[25] P. Molnar and H. Lyon-Caent, "Fault plane solutions of earthquakes and active tectonics of the Tibetan Plateau and its margins," Geophysical Journal International, vol. 99, no. 1, pp. 123-154, 1989.

[26] R. Armijo, P. Tapponnier, and T. Han, "Late Cenozoic rightlateral strike-slip faulting in southern Tibet," Journal of Geophysical Research: Solid Earth, vol. 94, no. B3, pp. 27872838, 1989.

[27] R. Kan, S. Zhang, F. Yan, and L. Yu, "Present tectonic stress field and its relation to the characterisitics of recent tectonic activity in southwestern China," Acta Geophsical Sinica, vol. 20, no. 2, pp. 96-107, 1977.

[28] O. Heidbach, M. Rajabi, K. Reiter, M. Ziegler, and MSM Team, World Stress Map Database Release 2016, GFZ Data Service, Potsdam, Germany, 2016.

[29] Y. W. S. Wang, Y. Li, and M. Xu, "The study of the evolution of neotectonic stress fields and reactivities of the main deep fractures in Hutiaoxia region," Mineralogy and Petrology, vol. 18, pp. 80-84, 1998.

[30] Y. Lv, H. Liao, Q. Su, and L. Wang, "The recent crustal deformation in Sichuan-Yunnan Rhombic block boundary," Earthquake Research in China, vol. 28, no. 1, pp. 28-37, 2002.

[31] L. Wang, Q. Wang, Y. Zhang, and Y. Wang, "Analysis of current activity of main faults in Yunnan region based on GPS," Journal of Institute of Disaster Prevention, vol. 18, no. 1, pp. 1-8, 2016.

[32] C. Guo, Engineering Geological Research on the Jinsha River Valley Section of the Yunnan-Tibet Railway, Chinese Academy of Geological Sciences, Beijing, China, 2007.

[33] Y. Wang, S. Wang, and Y. Li, "Neotectonic characteristics of the zhongdian-lijiang region, yunnan," Journal of Chengdu University of Technology, vol. 26, no. 1, pp. 68-72, 1999.

[34] L. Xue, B. Tang, and C. Mu, "Review of high stresses and rock burst problems," Technology of Highway and Transport, vol. 3, pp. 51-58, 1987.

[35] E. M. Anderson, The Dynamics of Faulting and Dyke Formation with Application to Britain, University of Edinburgh, Edinburgh, Scotland, 1951.

[36] X. Liu, Y. Fang, and D. Cai, "Friction coefficient of fault gouge in six faults in China," Northwestern Seismological Research, vol. 3, no. 1, pp. 23-26, 1987.

[37] M. D. Zoback and J. H. Healy, "Friction, faulting and in-situ stress,” Annales Geophysical, vol. 2, no. 6, pp. 689-698, 1984. 
[38] M. D. Zoback and S. Hickman, "In situ study of the physical mechanisms controlling induced seismicity at Monticello Reservoir, South Carolina," Journal of Geophysical Research: Solid Earth, vol. 87, no. B8, pp. 6959-6974, 1982.

[39] H. Xie, Y. Ju, and L. Li, "Criteria for strength and structural failure of rocks based on energy dissipation and energy release principles," Chinese Journal of Rock Mechanics and Engineering, vol. 24, no. 17, pp. 3003-3010, 2005.

[40] H. Mao, "Testing of ground stress of tunnel and analysis of tendentiousness of rock outburst," Journal of Railway Engineering Society, vol. 3, pp. 64-67, 2011.

[41] Z. Liu, Y. Zhu, and W. Li, "Mechanism and classification criterion for large deformation of squeezing ground tunnels," Chinese Journal of Geotechnical Engineering, vol. 30, no. 5, pp. 690-697, 2008. 